\title{
Brand Congruity and Comparative Advertising: When and Why Comparative Advertisements Lead to Greater Elaboration
}

\author{
Joseph R. Priester \\ Department of Marketing \\ University of Michigan \\ John Godek \\ Department of Marketing \\ University of Oregon \\ DJ Nayakankuppum \\ Department of Marketing \\ University of Iowa \\ Kiwan Park \\ Department of Marketing \\ University of Michigan
}

\begin{abstract}
Two experiments are conducted to examine when and why comparative advertisements lead to elaboration. Comparative advertisements in which the sponsor brand and the comparison brand are perceived to be dissimilar lead to greater elaboration, as evidenced by differences in argument quality, than comparative advertisements in which the sponsor and comparison brands are perceived to be similar. This pattern is particularly strong for those individuals not chronically predisposed to elaborate (low need for cognition), whereas those individuals chronically predisposed to elaborate (high need for cognition) elaborate the ads regardless of comparison composition. Results are consistent with our proposed brand congruity explanation.
\end{abstract}

Often the goal of advertising is to present information in a manner such that attitudes toward a brand are changed. This can be a particularly challenging goal, especially for relatively new brands, of which consumers are likely to be unfamiliar. An advertising format that has emerged as one means by which to accomplish this goal is comparative advertising (e.g., Belch, 1981; Grewal, Kavanoor, Fern, Costley, \& Barnes, 1997; Pechmann \& Ratneshwar, 1991; Wilkie \& Farris, 1975). Comparative advertising occurs when one brand (referred to as the sponsor brand) compares itself to another brand (re-

Requests for reprints should be sent to Joseph R. Priester, 701 Tappan Street, Ann Arbor, MI 48109-1234. E-mail: priester@umich.edu, or John Godek, Department of Marketing, University of Oregon, 376 Gilbert Hall, Eugene, OR 97403. E-mail: jgodek@uoregon.edu ferred to as the comparison brand). Although comparative advertising has typically been used by relatively unknown brands (comparing themselves to well-known brands), it has become increasingly common for even well-known brands to employ comparative advertising (comparing themselves to other well-known brands).

\section{COMPARATIVE ADVERTISING AND ELABORATION}

Comparative advertising is a potentially powerful tactic, in part, because research has demonstrated that comparative advertising engenders greater elaboration of the advertise- 
ment than noncomparative advertising (Dröge, 1989; Pechmann \& Esteban, 1994). Contemporary persuasion research has revealed that the process by which an attitude is changed can differ in terms of elaboration, and differences in elaboration can lead to differences in attitude strength, such that thoughtfully formed or changed attitudes (i.e., those attitudes that are the result of elaboration) are more likely to guide behavior than nonthoughtfully formed or changed attitudes (for reviews, see Myers-Levy \& Malaviya, 1999; Petty, Haugtvedt, \& Smith, 1995; Petty, Priester, \& Wegener, 1994; Petty \& Wegener, 1998, 1999; Priester \& Fleming, 1997; Priester, Nayakankuppam, Flemming, \& Godek, 2004). As such, comparative advertisements can be used to produce strong attitudes toward the sponsor brand. In this article, we investigate the question of when and why comparative advertising is associated with greater elaboration.

\section{THE HIGH-MARKET SHARE BRAND EXPLANATION}

The commonly accepted explanation for this influence of comparative advertising on elaboration focuses on the familiarity of the comparison brand. Specifically, the explanation has been advanced that the presence of a high-market share (and thus familiar) comparison brand induces greater feelings of relevance toward the ad, and these feelings of relevance prompt increased elaboration. Pechmann and Esteban (1994) provided a succinct summary of this explanation (p. 406).

Comparative ads typically compare low-share brands to the leading brands on the market because the leading brands have more equity (Aaker \& Keller, 1990). That is, market leaders are more familiar to consumers, are more frequently purchased, and are generally perceived to have more desirable attributes (Pechman \& Ratneshwar, 1992). Thus, naming (vs. not naming) a leading competitor brand should, presumably, enhance an ad's intrinsic relevance. That should, in turn, make subjects more motivated to read or listen to the advertiser's claims (Dröge 1989; Muehling, Stoltman, \& Grossbart, 1990; Pechmann \& Stewart, 1990; 1991).

Thus, comparative ads are hypothesized to lead to greater elaboration because of greater relevance, which is caused by the presence of a high-market share (familiar) brand.

\section{EVIDENCE IN SUPPORT OF THE HIGH-MARKET SHARE BRAND EXPLANATION}

This explanation is consistent with the two studies that have examined the influence of comparative advertising on elaboration. Dröge (1989) and Pechmann and Esteban (1994) both manipulated whether an advertisement, sponsored by an unfamiliar brand, was noncomparative or comparative. In the comparative advertisement conditions, the comparison brand was familiar. Both studies found evidence in support of the hypothesis that comparative advertisements lead to greater elaboration than noncomparative advertisements. Dröge (1989) found that cognitive responses better predicted attitudes associated with the comparative than the noncomparative advertisements, and Pechmann and Esteban (1994) found that argument quality had greater impact on attitudes when associated with the comparative than the noncomparative advertisements.

\section{AMBIGUITY OF THE EVIDENCE}

One feature that is particularly notable about each of these studies is that they both compare an advertisement for an unfamiliar brand in the noncomparative advertisement condition to an advertisement comparing an unfamiliar brand to a familiar brand in the comparative advertisement condition. Given this evidence, the possibility arises that the influence of comparative advertising on elaboration is the result of the presence of a high-market share brand (as hypothesized), or instead, is the result of the comparison of dissimilar (i.e., an unfamiliar brand comparing itself to a familiar brand) brands. Note that both explanations are consistent with the evidence for the influence of comparative advertisements on elaboration. We seek to investigate which explanation better accounts for the data.

\section{EVIDENCE INCONSISTENT WITH THE HIGH-MARKET SHARE EXPLANATION}

The ability of the high-market share brand explanation to account for why comparative advertisements lead to greater elaboration is possibly questioned by the results of Iyer (1988). Iyer manipulated the familiarity of both the sponsor and the comparative brands. The commonly accepted explanation that the presence of a high-market share brand leads to greater elaboration would predict that the comparative advertisement in which both the sponsoring brand and the comparison brands are familiar should be elaborated at least as much, if not more, than the comparative advertisement in which the sponsoring brand is unfamiliar and the comparison brands are familiar. That is, the presence of two familiar brands should be associated with as much, if not greater, relevance than the presence of one familiar brand. The results, however, are not necessarily consistent with this prediction.

Iyer (1988) in addition manipulated the verbal content of the advertisement. Although not conceptualized this way, the factual conditions of the verbal content manipulation appear to be more cogent and compelling than the evaluative conditions of the verbal content manipulation. If this is the case, 
one could use the manipulation of verbal content in a manner similar to the manipulation of argument quality - differences between verbal content conditions could be indicative of different levels of elaboration.

Examined in this way, the results suggest that the comparative advertisement of an unfamiliar sponsor comparing itself to familiar brands is associated with greater elaboration (difference factual-evaluative verbal content $=2.6$ ) than the comparative advertisement of a familiar sponsor comparing itself to other familiar brands (difference factual-evaluative verbal content $=$ 0.7 ). Thus, if indeed the factual verbal conditions are stronger than the evaluative verbal conditions, this finding would raise questions about the commonly accepted explanation for why comparative advertisements are associated with greater elaboration. Such an interpretation of Iyer (1988) rests on the conjecture that the verbal manipulation is also manipulating the quality of the advertisement messages.

To examine this conjecture, we conducted a preliminary study. As predicted, the factual verbal condition produced a more positive cognitive response profile and was perceived to be stronger than the evaluative verbal condition. This support for the interpretation of the Iyer (1988) results suggests the need for a new explanation for the influence of comparative advertising on elaboration.

\section{ALTERNATIVE EXPLANATION: BRAND CONGRUITY}

A growing body of research suggests that differences in congruity can influence evaluation and elaboration of products (see, e.g., Campbell \& Goodstein, 2001; Houston, Childers, \& Heckler, 1987; Myers-Levy \& Tybout, 1989; Ozanne, Brucks, \& Grewal, 1992; Peracchio \& Tybout, 1996; Sujan, 1985). Of greatest importance to this argument is the finding that products that are moderately incongruent from a product category schema receive greater attention than products that are either congruent or extremely incongruent from a product category.

Although this research has focused on the relation between a brand and a product category schema, we suggest a natural extension: Namely, we propose that a similar process may underlie the relation between two advertised brands. That is, we suggest that the congruity that exists between brands may similarly influence elaboration, such that moderately incongruent brand comparisons result in greater elaboration than congruent brand comparisons. Thus, we propose that brand-to-brand incongruity (i.e., comparison at the same level in categorization schema) can evoke processes similar to the brand-to-product category schema. We refer to this extension as brand congruity.

As such, brand congruity possibly provides an explanation consistent with the Iyer (1988) as well as the Dröge (1989) and Pechmann and Esteban (1994) findings. Both the Dröge (1989) and Pechmann and Esteban (1994) findings found greater elaboration when the comparative advertisement was composed of a familiar and an unfamiliar brand. That is, brand incongruity was associated with elaboration. Similarly, Iyer (1988) found greater elaboration when the comparative advertisement was composed of a familiar and an unfamiliar brand than when the comparative brand was composed of two familiar brands. Again, brand incongruity was associated with greater elaboration than brand congruity. Thus, brand congruity possibly provides an explanation that is more consistent with the data than the high-market share explanation.

\section{TEST OF THE ALTERNATIVE EXPLANATIONS}

To examine which of these explanations seems to best account for the influence of comparative advertising on elaboration, it is desirable to construct two comparative advertisements that vary in terms of familiarity (and thus relevance) and congruity. Specifically, the high-market share explanation suggests that the greater the relevance, the greater the probability of elaboration, whereas the brand congruity explanation suggests that the greater the brand incongruity, the greater the probability of elaboration. Given these different predictions, a strong test of the competing predictions is provided by a case in which one comparative advertisement is perceived to be more relevant (but congruent), and the other comparative advertisement is perceived to be less relevant (but incongruent)

Pretesting established that such a situation is provided by the case in which a high-market share (and thus familiar) sponsor brand compares itself to either another high-market share (and thus familiar and congruent) brand or to a low-market share (and thus unfamiliar and incongruent) brand. The familiar sponsor-familiar comparison brand advertisement results in perceptions of greater relevance (and similarity) than the familiar sponsor-unfamiliar comparison brand advertisement, and the familiar sponsor-unfamiliar comparison brand advertisement results in perceptions of less similarity (and less relevance) than the familiar sponsor-familiar comparison brand.

\section{EXPERIMENT 1}

Experiment 1 was designed to test which of the explanations best account for the influence of comparative advertising on elaboration. Experiment 1 manipulated whether a high-market share (and thus familiar) brand compared itself to another high-market share (and thus familiar) brand or instead to a low-market share (and thus unfamiliar) brand. In addition, we manipulated argument quality to provide inferences as to the extent of elaboration. 


\section{The Manipulation of Argument Quality}

The manipulation of argument quality has emerged as a means by which to infer differences in elaboration (see Petty \& Cacioppo, 1986, pp. 30-44; Petty, Wegener, Fabrigar, Priester, \& Cacioppo, 1993; Petty, Wells, \& Brock, 1976). The logic of manipulating argument quality to assess the extent of thinking is that when individuals are exposed to a message under specific conditions that foster elaboration, the quality of the arguments should have a larger impact on attitudes than under conditions that hinder elaboration (i.e., when elaboration is low). In short, argument quality is used as a metric by which to measure differences in the extent that individuals are elaborating the content of the persuasive message: The greater the influence of argument quality, the more presumed elaboration has led to that influence. The advantage of a manipulated approach to indexing elaboration is that it overcomes alternative explanations (such as reverse causality) associated with measures of elaboration, such as cognitive responses (see Petty, Priester, \& Brinol, 2002; Petty et al., 1993).

In this case, we are interested in the Brand congruity $\times \mathrm{Ar}-$ gument quality interaction. If the high-market share explanation is responsible for the influence of comparative advertising on elaboration, there should emerge a brand congruity interaction with argument quality, such that the influence of argument quality is greater on attitudes when the brands are both high-market share (and thus more relevant and, at the same time, congruent). In contrast, if the brand congruity explanation is responsible, there should emerge a brand congruity interaction with argument quality, such that the influence of argument quality on attitudes is greater when the brands are incongruent.

\section{Participants and Design}

One hundred seventy-eight undergraduate marketing students at a large midwestern university participated for partial course credit. Participants were given a mock-up of a health magazine containing several articles and two advertisements. The second ad in the magazine was a comparative advertisement for a toothpaste. To create a moderate-involvement condition (i.e., those conditions under which comparative advertising is most likely to lead to greater elaboration), participants were given a cover story similar to that used in Pechmann and Esteban (1994). Specifically, participants read that

The university is considering implementing a health magazine for university students. Please skim through this short mock-up magazine as you normally might skim through a real health magazine. One of the ads in the magazine is for toothpaste, and marketers of this toothpaste may be giving out samples of it on college campuses next year.
Participants were randomly assigned to one of four cells of a 2 (argument quality, strong vs. weak) $\times 2$ (brand congruity, incongruent vs. congruent) between-participant design experiment. Immediately after reading the magazine, participants completed a questionnaire containing the dependent measures.

\section{Independent Variables}

Argument quality. Argument quality was manipulated such that half of the arguments contained strong messages in support of the sponsored brand and half of the arguments contained weak messages in support of the sponsored brand. The argument quality manipulation was identical to that used by Pechmann and Esteban (1994).

Brand congruity. The comparison brand was manipulated in the advertisement such that a high-market share brand (Crest) was compared to either another high-market share brand (Colgate), thus creating a brand-congruent advertisement, or to a low-market share brand (Zact), thus creating a brand-incongruent advertisement. In the high-market share comparison brand condition, text at the top of the page stated, "Why should you choose Crest Toothpaste instead of Colgate?" whereas in the low-market share comparison brand condition, the text stated, "Why should you choose Crest Toothpaste instead of Zact?"

The sponsor brand (Crest) was presented by a picture of a Crest tube of toothpaste that was displayed prominently in the middle of the page. The comparison brand (either Colgate or Zact) was presented by a picture of a tube of toothpaste that was displayed as one fourth the size of the sponsor ad in the bottom left portion of the page.

\section{Dependent Variables}

Attitude toward the sponsor brand was assessed on six 7-point scales. Each scale ranged from -3 to +3 . The anchors associated with -3 included bad, unpleasant, disagreeable, unsatisfactory, foolish, and harmful. The anchors associated with +3 included good, pleasant, agreeable, satisfactory, wise, and beneficial. Analysis revealed that the six scales were highly related (Cronbach's a $=0.97$ ). Thus, we created an overall sponsor-brand attitude measure by averaging the six scale responses. This approach resulted in one attitude measure, ranging from -3 to +3 .

\section{RESULTS}

The attitude measure was subjected to a 2 (brand congruity) $\times 2$ (argument quality) analysis of variance (ANOVA). Not surprising, there emerged a main effect for argument quality, such that attitudes were more positive as a result of strong $(X$ $=1.64)$ than weak $(X=-.01)$ arguments, $F(1,166)=66.34, p$ 
$<.0001$. Of greater theoretical importance, this main effect was qualified by the two-way interaction predicted by the brand congruity explanation, $F(1,166)=5.92, p<.02$. This two-way interaction was interpreted by examining the relative influence of argument quality on the two types of brand congruity. These analyses revealed that, as predicted by the brand congruity explanation, argument quality had a greater influence on attitudes when the brands were incongruent, $X_{\text {strong argument }}=1.77, X_{\text {weak argument }}=-0.34 ; F(1,85)=56.73, p$ $<.0001$, than congruent, $X_{\text {strong argument }}=1.51, X_{\text {weak argument }}=$ $0.37 ; F(1,81)=16.11, p<.001$. The results are presented in Figure 1.

\section{DISCUSSION}

Recall that Experiment 1 was conducted to test whether the high-market share explanation or the brand congruity explanation best accounted for the influence of comparative advertising on elaboration. As predicted by the brand congruity explanation, the cogency of the arguments embedded in the advertisement had a greater effect when the brands were incongruent than congruent. Based on Experiment 1, it is tempting to infer that comparative advertisements are associated with greater elaboration because of the brand congruity explanation rather than the presence of a high-market share brand. Before such an inference is accepted, it is wise to consider an alternative explanation to Experiment 1 . The sponsor brand for both of the comparative advertisements in Experiment 1 was a high-market share brand. It may be that the processes hypothesized by the high-market share explanation operate only when the sponsor brand of a comparative advertisement is a low-market share brand, whereas other processes, such as brand congruity, operate when the sponsor brand is a high-market share brand. We refer to this as the modified high-market share explanation. Such an explanation would suggest that the results of Experiment 1 were due to the choice of a
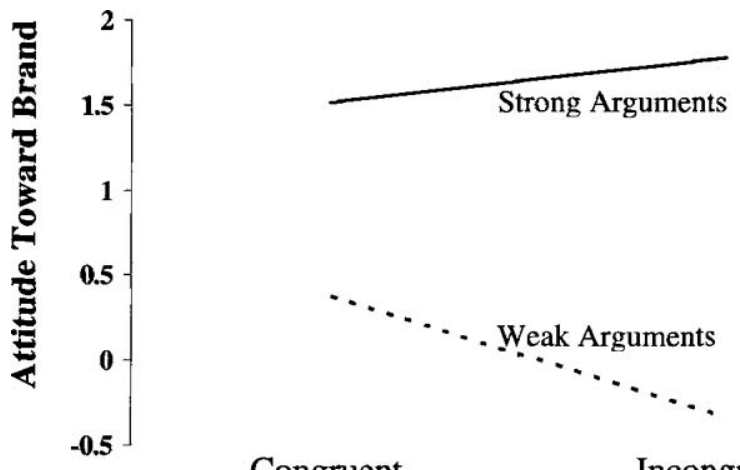

Congruent

Incongruent

\section{Brand Congruity}

FIGURE 1 Attitudes as a function of brand congruity and argument quality, Experiment 1. high-market share sponsor brand and, as such, did not provide an adequate test of the explanations.

If true, such an alternative explanation would make a specific prediction. Namely, the modified high-market share explanation would predict that the type of sponsor (high- vs. low-market share) should moderate the interaction found in Experiment 1. Specifically, if the results of Experiment 1 are unique to the use of a high-market share brand as sponsor, and the predictions associated with the high-market share explanation emerge when the sponsor brand is of low-market share, then there should emerge a Sponsor brand $\times$ Brand congruity $\times$ Argument quality interaction. In contrast, if the results of Experiment 1 emerged because brand congruity drives the influence of comparative advertising on elaboration, regardless of sponsor brand, then there should emerge only a brand congruity $\times$ argument quality interaction unmoderated by sponsor brand.

\section{Need for Cognition}

Before comparing the alternative hypotheses, it is important to note that variables that influence motivation to elaborate are often moderated by the propensity of an individual to chronically elaborate. Need for cognition has been developed as a means by which to measure such chronic tendencies (Cacioppo \& Petty, 1982; Cacioppo, Petty, Feinstein, \& Jarvis, 1996). Research has revealed that individuals high in need for cognition intrinsically enjoy elaboration and are likely to elaborate even information that is low in self-relevance (Cacioppo, Petty, Kao, \& Rodriguez, 1986). In contrast, individuals low in need for cognition do not intrinsically enjoy elaboration and are more likely to elaborate information only when variables increase their motivation to do so.

Thus, research has uncovered a consistent pattern whereby individuals high in need for cognition elaborate regardless of motivational factors, whereas individuals low in need for cognition elaborate when motivated to do so by variables that influence motivation (e.g., Petty, Fleming, Priester, \& Feinstein, 2001; Priester \& Petty, 1995; see Cacioppo et al., 1996). Given this research, we further hypothesize that our results will similarly be moderated by need for cognition, such that individuals high in need for cognition will elaborate regardless of brand congruity, whereas individuals low in need for cognition will be likely to demonstrate either the three-way interaction predicted by the high-market share explanation or the two-way interaction predicted by the brand congruity explanation.

\section{EXPERIMENT 2}

Experiment 2 was conducted to examine whether the results of Experiment 1 were due to the choice of a high-market share sponsor (consistent with a modified high-market share 
explanation) or instead generalized to low-market share sponsors as well. In addition, Experiment 2 examined whether individual differences in propensity to elaborate (i.e., need for cognition) moderated the differential elaboration processes, such that individuals high in need for cognition elaborated regardless of the type of comparative advertisement, whereas individuals low in need for cognition elaborated differentially, depending on the nature of the comparative advertisement.

\section{METHODS}

\section{Participants and Design}

One hundred thirty-nine undergraduate marketing students at a large midwestern university participated for partial course credit. Participants were given experimental materials identical to that of Experiment 1. Participants were randomly assigned to one of eight cells of a 2 (argument quality, strong vs. weak) $\times 2$ (brand congruity, incongruent vs. congruent) $\times$ 2 (sponsor brand, high vs. low-market share) experiment. In addition, participants were classified as being either high or low need in cognition. Thus, the study consisted of 16 cells in a 2 (need for cognition) $\times 2$ (argument quality) $\times 2$ (brand congruity) $\times 2$ (sponsor brand) between-participant factorial design experiment.

\section{Independent Variables}

Need for cognition. At the conclusion of the experimental session, participants completed the 18-item need for cognition scale (Cacioppo \& Petty, 1982). Scores ranged from (36) to (84), with a median of (65). A median split was conducted such that individuals with scores above the median were classified as high $(n=59)$ and those below the median were classified as low $(n=67)$.

Argument quality. Argument quality was manipulated in a manner identical to that of Experiment 1.

Brand congruity. Brand congruity was manipulated in a manner similar to that of Experiment 1, with the modification of manipulating both the sponsor and comparison brands. Thus, Crest was compared to Colgate and Zact (as in Experiment 1), and Zact was compared to Crest or Glee. The incongruent brand advertisements were those in which Crest compared itself to Zact, and Zact compared itself to Crest, whereas the congruent brand advertisements were those in which Crest compared itself to Colgate, and Zact compared itself to Glee.

Sponsor brand. The sponsor brand was manipulated to be either low (Zact) or high (Crest) in market share.

\section{Dependent Variables}

Attitudes. The same items used in Experiment 1 were used in Experiment 2. Analysis revealed that the six scales were highly related (Cronbach's a $=0.97$ ). Thus, we created an overall sponsor-brand attitude measure by averaging the six scale responses, resulting in one attitude measure, ranging from -3 to +3 .

\section{RESULTS}

\section{Attitude Toward Sponsor Brand}

The attitude measure was subjected to a 2 (need for cognition) $\times 2$ (brand congruity) $\times 2$ (argument quality) $\times 2$ (sponsor brand) ANOVA. Two main effects emerged from this analysis. There emerged a main effect for sponsor brand, such that participants were more positive toward high-market share $(X=0.81)$ than low-market share $(X=-.22)$ brands, $F(1,110)=17.93, p<.0001$. And not surprising, there also emerged a main effect for argument quality, such that attitudes were more positive as a result of strong $(X=0.94)$ than weak $(X=-.28)$ arguments, $F(1,110)=27.08, p<.0001$. Of greater theoretical importance, these main effects were qualified by a need for Cognition $\times$ Brand congruity $\times$ Argument quality interaction, $F(1,110)=6.71<.02$. The results for all 16 experimental conditions are presented in Table 1.

This three-way interaction was decomposed by examining the main effects and interactions for the high and low need for cognition participants separately (i.e., the main effects of brand congruity, sponsor brand, argument quality, and the resulting interactions were examined for high and low need for cognition participants). The results for those participants high in need for cognition revealed a simple effect for sponsor brand, $F(1,51)=14.1, p<.0001$. And, as predicted, participants high in need for cognition exhibited a simple effect for argument quality, demonstrating that strong arguments $(X=.9)$ were more persuasive than weak $(-.7)$, $F(1,51)=18.8, p<.0001$. This main effect of argument quality was not qualified by either the Brand congruity $\times$ Argument quality interaction, $F(1,51)=.6, p>.4$, the Sponsor $\times$ Argument quality interaction, $F(1,51)=0.58, p>.4$, or the Brand congruity $\times$ Sponsor brand $\times$ Argument quality interaction, $F(1,51)=.5, p>.5$, for the high need for cognition participants.

As predicted by the brand congruity explanation, the results for the low need for cognition participants revealed a significant Brand congruity $\times$ Argument quality interaction, $F(1,59)$ $=8.94, p<.005$, in addition to main effects for argument quality and sponsor brand. Decomposition of this interaction demonstrates that the influence of argument quality is greater for the incongruent, $F(1,31)=15.0, p<.0005$, than congruent, $F(1,28)=0.00, p>.9$, comparative advertisements. The results of this interaction are presented in Figure 2. 
TABLE 1

Means (and Standard Deviations) of Attitudes as a Function of Need for Cognition, Argument Quality, Brand Congruity, and Sponsor Brand (Experiment 2).

\begin{tabular}{|c|c|c|c|c|}
\hline \multirow{2}{*}{$\frac{\text { Argument Quality }}{\text { High Need for Cogniti }}$} & \multicolumn{2}{|c|}{ Low Market Share Sponsor } & \multicolumn{2}{|c|}{ High Market Share Sponsor } \\
\hline & & & & \\
\hline Strong & $\begin{array}{c}1.04(0.6) \\
n=8\end{array}$ & $\begin{array}{c}-0.11(1.4) \\
n=9\end{array}$ & $\begin{array}{c}1.43(0.6) \\
n=10\end{array}$ & $\begin{array}{c}1.26(0.6) \\
n=7\end{array}$ \\
\hline Weak & $\begin{array}{c}-1.52(1.3) \\
n=8\end{array}$ & $\begin{array}{c}-1.63(1.2) \\
n=5\end{array}$ & $\begin{array}{c}0.31(2.2) \\
n=7\end{array}$ & $\begin{array}{c}0.20(2.3) \\
n=5\end{array}$ \\
\hline $\begin{array}{l}\text { Brand Congruity } \\
\text {. }\end{array}$ & Congruent & Incongruent & Congruent & Incongruent \\
\hline & $\begin{array}{c}0.50(1.4) \\
n=6\end{array}$ & $\begin{array}{c}0.71(0.8) \\
n=7\end{array}$ & $\begin{array}{c}0.33(1.0) \\
n=7\end{array}$ & $\begin{array}{c}2.19(0.78) \\
n=8\end{array}$ \\
\hline Weak & $\begin{array}{c}-0.06(0.6) \\
n=8\end{array}$ & $\begin{array}{c}-0.85(1.6) \\
n=9\end{array}$ & $\begin{array}{c}0.91(1.3) \\
n=11\end{array}$ & $\begin{array}{c}-0.22(2.0) \\
n=11\end{array}$ \\
\hline Brand Congruity & Congruent & Incongruent & Congruent & Incongruent \\
\hline
\end{tabular}

The results of the low need for cognition participants were not supportive of the modified high-market share explanation. Specifically, further analyses revealed that, consistent with the brand congruity explanation, the quality of the arguments embedded within the advertisement significantly influenced attitudes when either the sponsor brand was high-market share and the comparative brand was low, $X_{\text {strong }}$ arguments $=2.19, X_{\text {weak arguments }}=-0.23 ; F(1,17)=10.2, p<$ .005 , or when the sponsor brand was low-market share and the comparative brand was high, $X_{\text {strong arguments }}=0.71, X_{\text {weak }}$ arguments $=-0.85 ; F(1,14)=5.45, p<0.5$, whereas the quality of the arguments did not influence attitudes when either the sponsor brand was high-market share and the comparative brand was high, $X_{\text {strong arguments }}=0.33, X_{\text {weak arguments }}=0.91$; $F(1,16)=0.96, p=n s$, or when the sponsor brand was low-market share and the comparative brand was low-market share, $X_{\text {strong arguments }}=0.50, X_{\text {weak arguments }}=-0.06 ; F(1,12)=$ $1.05, p=n s$. That is, argument quality only influenced attitudes when the brands were incongruent and had no effect when the brands were congruent.
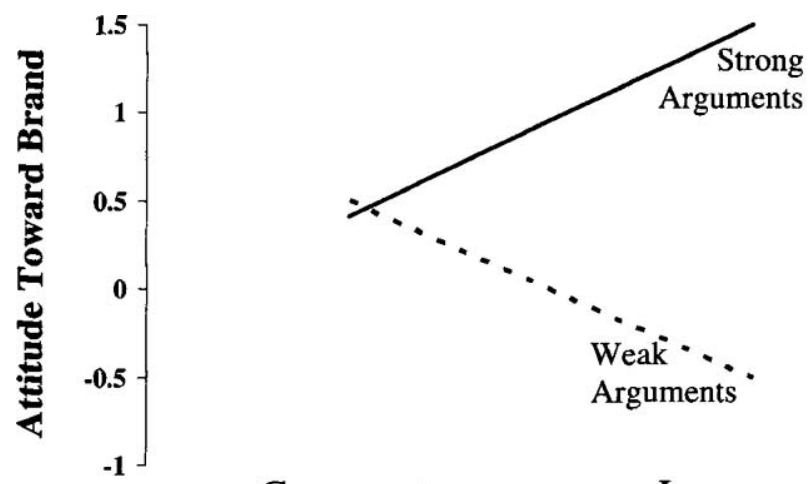

Congruent

Incongruent

\section{Brand Congruity}

FIGURE 2 Attitudes as a function of argument quality and brand congruity for low need for cognition participants, Experiment 2.

\section{DISCUSSION}

Recall that Experiment 2 was conducted to examine whether the results of Experiment 1 were limited to the conditions under which the sponsor brand of a comparative advertisement is high-market share (consistent with the modified high-market share explanation) or instead extended to comparative advertisements in which the sponsor brand was low-market share (consistent with the brand congruity explanation). The results of Experiment 2 are straightforward: Elaboration of advertising content emerges more when there exists incongruence between the sponsor and comparative brand than when there exists congruence, regardless of the market share of the sponsor brand. Thus, the results of Experiment 2 provide additional evidence for the brand congruity explanation of why comparative advertisements are associated with greater elaboration.

Recall, also, that Experiment 2 was conducted to examine whether individual differences in propensity to elaborate moderated the influence of comparative advertisement composition on elaboration. As predicted, this moderation emerged. Individuals who chronically enjoy thinking (i.e., high in need for cognition) elaborated the advertisement regardless of its composition. In contrast, it was the individuals who do not intrinsically enjoy thinking (i.e., low in need for cognition) whose elaboration of the advertisement was systematically influenced by its composition.

\section{GENERAL DISCUSSION}

At the most basic, this research provides a new explanation for why comparative advertisements have been found to lead to greater elaboration. This explanation is based on an extension of congruity theory. We hypothesize, and find support for the idea that similar to how brand deviation from a schema can lead to greater scrutiny, so too can incongruent brand compari- 
son prompt greater elaboration. We refer to this as brand congruity. What is particularly compelling about this explanation is that it can account not only for the results of this article, but also provides an explanation consistent with the Iyer (1988), as well as the Dröge (1989) and Pechmann and Esteban (1994) findings. Thus, at its core, this article provides an explanation for why comparative advertisements have been found to be associated with greater elaboration. It is not the comparison per se that prompts elaboration, or the presence of a high-market share brand. Rather, it is the presence of relatively incongruent brands that leads to increased elaboration. As such, brand congruity explanation offers not only an explanation for past findings, but also provides theoretical and practical guidance as to when comparative advertisements will prompt recipients to thoughtfully consider the advertising content.

This research also provides evidence of the many determinants of advertisement elaboration. Just as Pechmann and Esteban (1994) found that manipulation of high personal relevance led to greater elaboration regardless of advertisement type, this research suggests that individuals with high need for cognition are likely to elaborate advertisements regardless of motivational factors (assuming that they possess the requisite ability). Because they enjoy thinking, they are likely to think unless distracted, regardless of what motivational factors are present. That is, they bring their own motivation to the advertisement. In sharp contrast, individuals low in need for cognition lack such intrinsic motivation. It is for them that features of the advertisement, such as brand congruity, prompt and guide elaboration. Such findings provide both conceptual and practical insight into how advertising influences its recipients.

This new understanding of why comparative advertisements influence elaboration provides important managerial insights as to when comparative advertisements will be associated with greater elaboration. Specifically, it is only when a low-market share sponsor compares itself to a high-market share competitor or, alternatively, when a high-market share sponsor compares itself to a low-market share competitor that comparative advertisements will prompt greater elaboration. As such, the use of comparative advertisements that compare high-market share brands to other high-market share brands may be reducing, rather than increasing, the effectiveness of their advertisements. That is, the acceptance of the high-market share explanation may well have led to current advertising practices, in which high-market share brands compare themselves to other high-market share brands. The brand congruity explanation suggests that such a strategy may not only be unwarranted, but even counteproductive.

Future research might profitably examine the mechanisms underlying brand congruity. For example, is it the case that brand incongruity influences confidence in one's attitude, which in turn influences subsequent elaboration? And what dimensions of the brands trigger perceptions of congruity or incongruity? Such questions will advance what is known about brand congruity and, perhaps, congruity theory as well.

\section{ACKNOWLEDGMENTS}

This research was supported by a grant from the University of Michigan Business School to the first author. Portions of this research were presented at the 2000 Society for Consumer Psychology conference.

\section{REFERENCES}

Aaker, D. A., \& Keller, K. L. (1990). Consumer evaluations of brand extensions. Journal of Marketing, 54(1), 27-41.

Belch, G. E. (1981). An examination of comparative and noncomparative television commercials: The effects of claim variation and repetition on cognitive response and message acceptance. Journal of Marketing Re. search, 18(3), 333-349.

Cacioppo, J. T., \& Petty, R. E. (1982). The need for cognition. Journal of Personality and Social Psychology, 42(1), 116-131.

Cacioppo, J. T., Petty, R. E., Feinstein, J. A., \& Jarvis, W. B. G. (1996). Dispositional differences in cognitive motivation: The life and times of individuals varying in need for cognition. Psychological Bulletin, $119(2)$, 197-253.

Cacioppo, J. T., Petty, R. E., Kao, C. F., \& Rodriguez, R. (1986). Central and peripheral routes to persuasion: An individual difference perspective. Journal of Personality and Social Psychology, 5I(5), 1032-1043.

Campbell, M. C., \& Goodstein, R. C. (2001). The moderating effect of perceived risk on consumers' evaluations of product incongruity: Preference for the norm. Journal of Consumer Research, 28(3), 439-449.

Dröge, C. (1989). Shaping the route to attitude change: Central processing through comparative versus noncomparative advertising. Journal of Marketing Research, 26(2), 193-204.

Grewal, D., Kavanoor, S., Fern, E. F., Costley, C., \& Barnes, J. (1997). Comparative versus noncomparative advertising: A meta-analysis. Journal of Marketing, 6I(4), 1-15.

Houston, M. J., Childers, T. L., \& Heckler, S. E. (1987). Picture-word consistency and the elaborative processing of advertisements. Journal of Marketing Research, 24(4), 359-369.

Iyer, E. S. (1988). The influence of verbal content and relative newness on the effectiveness of comparative advertising. Journal of Advertising, I7(3), 15-21.

Meyers-Levy, J., \& Malaviya, P. (1999). Consumers' processing of persuasive advertisements: An integrative framework of persuasion theories. Journal of Marketing, 63, 45-60.

Meyers-Levy, J., \& Tybout, A. M. (1989). Schema congruity as a basis for product evaluation. Journal of Consumer Research,6(1), 39-54.

Muehling, D. D., Stoltman, J. J., \& Grossbart, S. (1990). The impact of comparative advertising on levels of message involvement. Journal of Advertising, 19(4), 41-50

Ozanne, J. L., Brucks, M., \& Grewal, D. (1992). A study of information search behavior during the categorization of new products. Journal of Consumer Research, I8(4), 452-463

Pechmann, C., \& Esteban, G. (1994). Persuasion processes associated with direct comparative and noncompartitive advertising and implications for advertising effectiveness. Journal of Consumer Psychology, 2(4), $403-432$.

Pechmann, C., \& Ratneshwar, S. (1991). The use of comparative advertising for brand positioning: Association versus differentiation. Journal of Consumer Research, I8(2), 145-159.

Pechmann, C., \& Ratneshwar, S. (1992). Covariation judgments: Theory or Data Driven? Journal of Consumer Research, 19(3), 373-386.

Pechmann, C., \& Stewart, D. W. (1990). The effects of comparative advertising on attention, memory, and purchase intentions. Journal of Consumer Research, 17(2), 180-191. 
Pechmann, C., \& Stewart, D. W. (1991). How direct comparative ads and market share affect brand choice. Journal of Advertising Research, 3I(6), 47-55.

Peracchio, L. A., \& Tybout, A. M. (1996). The moderating role of prior knowledge in schema-based product evaluation. Journal of Consumer Research, 23(3), 177-192.

Petty, R. E., \& Cacioppo, J. T. (1986). Communication and persuasion: Central and peripheral routes to attitude change. New York: Springer/Verlag.

Petty, R. E., Fleming, M. A., Priester, J. R., \& Feinstein, A. H. (2001). Individual- versus group-interest violation: Surprise as a determinant of argument scrutiny and persuasion. Social Cognition, 19(4), 418-442.

Petty, R. E., Haugtvedt, C. P., \& Smith, S. M. (1995). Elaboration as a determinant of attitude strength: Creating attitudes that are persistent, resistant, and predictive of behavior. In R. E. Petty \& J. Krosnick (Eds.), Attitude strength: Antecedents and consequences, Hillsdale, NJ: Lawrence Erlbaum Associates, Inc.

Petty, R. E., Priester, J. R, \& Brinol, P. (2002). Mass media attitude change: implications of the elaboration likelihood model of persuasion. In J. Bryant \& D. Zillmann (Eds.), Media effects: Advances in theory and research (2nd ed., pp. 155-198). Hillsdale, NJ: Lawrence Erlbaum Associates, Inc.

Petty, R. E., Priester, J. R., \& Wegener, D. T. (1994). Cognitive processes in attitude change. In R. S. Wyer \& T. K. Srull (Eds.), The handbook of social cognition (2nd ed.). Hillsdale, NJ: Lawrence Erlbaum Associates, Inc.

Petty, R. E., \& Wegener, D. T. (1998). Attitude change: Multiple roles for persuasion variables. In D. Gilbert, S. Fiske, \& G. Lindzey (Eds.), Hand- book of social psychology (4th ed., Vol. 1, pp. 323-390), Boston, MA: McGraw-Hill.

Petty, R. E., \& Wegener, D. T. (1999). The elaboration likelihood model: Current status and controversies. In S. Chaiken \& Y. Trope (Eds.), Dual process theories in social psychology (pp. 41-72). New York: Guilford.

Petty, R. E., Wegener, D. T., Fabrigar, L. R., Priester, J. R., \& Cacioppo, J. T. (1993). Conceptual and methodological issues in the elaboration likelihood model of persuasion: A reply to the Michigan State critics. Communication Theory, 3, 336-363.

Petty, R. E., Wells, G. L., \& Brock, T. C. (1976). Distraction can enhance or reduce yielding to propaganda: Thought disruption versus effort justification. Journal of Personality and Social Psychology, 34(5), 874-884.

Priester, J. R., \& Fleming, M. A. (1997). Artifact or meaningful theoretical constructs? Examining evidence for nonbelief- and belief-based attitude change processes. Journal of Consumer Psychology, 6(1), 67-76.

Priester, J. R., \& Fleming, M. A. (1997). Artifact or meaningful theoretical constructs? Examining evidence for nonbelief-and belief-based attitude change processes. Journal of Consumer Psychology, 6(1), 67-76.

Priester, J. R., Nayakankuppam, D., Fleming, M. A., \& Godek, J. (2004). The $\mathrm{A}^{2} \mathrm{SC}^{2}$ Model: The Influence of attitudes and attitude strength on consideration and choice. Journal of Consumer Research, 19(3), 373-386.

Sujan, M. (1985). Consumer knowledge: Effects on evaluation strategies mediating consumer judgments. Journal of Consumer Research, 12(1), $31-46$

Wilkie, W. L. \& Farris, P. W. (1975). Comparison advertising: Problems and potential. Journal of Marketing, 39(1), 7-15. 